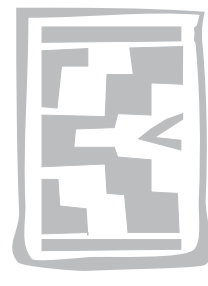

\title{
Clinical, humoral and IFN $\gamma$ responses of cattle to infection with Mycoplasma mycoides var. mycoides small colony and attempts to condition the pathogenesis of the infection
}

\author{
M. SCACCHIA ${ }^{1}$, F. SACCHINI ${ }^{1}$, G. FILIPPONI ${ }^{1}$, M. LUCIANI ${ }^{1}$, R. LELLI ${ }^{1}$, G. TJIPURA-ZAIRE ${ }^{2}$, \\ A. DI PROVVIDO ${ }^{1}$, A. SHININGWANE ${ }^{2}$, F. NDIIPANDA ${ }^{2}$, A. PINI ${ }^{1}$, V. CAPORALE ${ }^{1}$ \\ and O.J.B. HÜBSCHLE ${ }^{2}$
}

\begin{abstract}
SCACCHIA, M., SACCHINI, F., FILIPPONI, G., LUCIANI, M., LELLI, R., TJIPURA-ZAIRE, G., DI PROVVIDO, A., SHININGWANE, A., NDIIPANDA, F., PINI, A., CAPORALE, V. \& HÜBSCHLE, O.J.B. 2007. Clinical, humoral and IFN $\gamma$ responses of cattle to infection with Mycoplasma mycoides var. mycoides small colony and attempts to condition the pathogenesis of the infection. Onderstepoort Journal of Veterinary Research, 74:251-263

Contagious bovine pleuropneumonia (CBPP), caused by Mycoplasma mycoides var. mycoides small colony (MmmSC), is one of the most important diseases of cattle in Africa.

The role of innate or acquired cell mediated and humoral immunity in conferring protection against MmmSC infection has not yet been elucidated. On the other hand, the pathological lesions caused by the aetiological agent have been considered indicative of an immunopathological process.

In this study ten naïve cattle were exposed to in-contact infection with animals infected by intubation with a strain of $M m m S C$. Clinical signs, antibody response, IFN $\gamma$ release and pathological changes at necropsy were analysed and compared with the events following in-contact infection of an equal number of animals kept under daily treatment with cyclosporine for the entire observation period of 84 days. Cyclosporine is a suppressor of the immune response related to the T-cell system.

Under the conditions of the experiment, cyclosporine appeared to condition the pathogenesis of CBPP by delaying the events that follow infection, bringing further support to the possibility that the immune response may have an impact on the disease outcome.
\end{abstract}

Keywords: Contagious bovine pleuropneumonia, cyclosporine, IFN $\gamma$, intubation, immunosuppression

\section{INTRODUCTION}

Contagious bovine pleuropneumonia (CBPP) caused by Mycoplasma mycoides var. mycoides small colony $(\mathrm{MmmSC})$ remains one of the most important diseases of cattle in Africa. It affects cattle and domestic buffaloes (Bubalus bubalis), causing death

1 Istituto Zooprofilattico Speerimntale dell'Abruzzo e del Molise "G. Caporale", Via Campo Boario, 64100 Teramo, Italy

2 Central Veterinary Laboratory, Ministry of Agriculture, Water and Forestry, Goethe St., Windhoek, Namibia

Accepted for publication 2 April 2007-Editor and substantial losses in productivity (Provost, Perreau, Breard, Legoff, Martel \& Cottew 1987; Santini, Visaggio, Farinelli, Di Francesco, Guarducci, D’Angelo, Scacchia \& Di Giannatale 1992).

CBPP made its reappearance in southern Europe, Spain, Portugal and Italy in the second half of the $20^{\text {th }}$ century where it was eradicated through a policy of disease surveillance, movement control of cattle and stamping out.

The mycoplasma is responsible for a severe inflammatory lung reaction with an accompanying serofibrinous pleuritis, usually affecting only one lung. However, the reactivity of cattle is variable with re- 
spect to clinical reaction, immune response and mortality. The disease may have a long incubation period, lasting several months, and it often has a subacute or chronic course (Provost et al. 1987). On a few occasions, the aetiological agent has also been isolated from sheep and goats suffering from mastitis or pneumonia (Brandao 1995; Srivastava, Thiaucourt, Singh, Sunder \& Singh 2000); whether they play a role in the epidemiology of the disease is questionable.

In Africa, where stamping out and control of animal movements is difficult to implement, vaccination with the live attenuated T1/44 strain is the method of choice. Vaccine however, has limited efficacy as the immunity conferred is of short duration and vaccination must be repeated annually (Thiaucourt, Yaya, Wesonga, Hübschle, Tualasne \& Provost 2000). The T1/44 strain maintains a level of pathogenicity when administered to cattle by the intratracheal route (Hübschle, Lelli, Frey \& Nicholas 2002). The $\mathrm{T} 1 / 44$ vaccine is nevertheless used in absence of a better product. The development of new generation vaccines has so far not given satisfactory results (Abusugra, Wolf, Bolske, Thiaucourt \& Morein 1997; Hübschle, Tjipura-Zaire, Abusugra, Francesca, Mettler, Pini \& Morein 2003; Nicholas, Tijpura-Zaire, Mbulu, Scacchia, Mettler \& Frey 2004).

Balcer \& Dedieu (2000), in analysing cell mediated immune response induced by $\mathrm{MmmSC}$, came to the conclusion that the poor protection conferred by $\mathrm{T} 1 / 44$ vaccine had to be correlated to the low cellmediated immune response elicited. The role of innate or acquired cell mediated and humoral immunity in conferring protection has, however, not yet been elucidated (Roberts \& Windsor 1974; Tulasne, Litamoi, Morein, Dedieu, Palya, Yami, Abusugra, Sylla \& Bensaid 1996).

Even though the pathological lesions which occur following infection are considered to be a manifestation of an immunopathological process (Gourlay \& Safrine 1966; Adegboye 1978; Howard \& Taylor 1985), an understanding of the pathogenetic pathway leading to the disease process has so far been elusive.

More recently, Dedieu, Balcer-Rodrigues, Yaya, Hamadou, Cisse, Diallo \& Niang (2005) have shown that activation of CD4 T-cells can be demonstrated in all experimentally infected cattle whereas release of IFN $\gamma$ was associated with recovered animals that had chronic lesions. In their experiment, acute disease, followed by death, was associated with a decreased ability to produce IFN $\gamma$.
On the assumption that the immune response may have an impact on disease outcome, it was decided to test the effects of cyclosporine A (CsA) (Novartis Pharma AG) on cattle exposed to infection with a strain of $M m m S C$. The drug acts as a prodrug by binding to endogenous intracellular receptors (immunophilins). The resulting complex targets the protein phosphatase that exerts the immunosuppressive action on the T-cell system (Baumann, Zenke, Wenger, Hiestand, Quesniaux, Andersen \& Schreier 1992).

\section{MATERIALS AND METHODS}

\section{Cattle}

The animal experiments were performed in Namibia at the Mashare experimental farm owned by the Ministry of Agriculture, Water and Forestry in the Kavango region, some $700 \mathrm{~km}$ north of the capital, Windhoek. The farm is situated within the animal disease restricted area in the north of the country, and is beyond the Transveterinary Cordon Fence.

The animal experimental protocol was performed in accordance with European legislation 86/609/CEE.

Twenty-nine cattle, 2 years of age or older from a commercial farming area of Namibia, free of CBPP for the last 70 years (Anon 1987), were clinically screened and their sera tested before they were moved to the Mashare farm. Serological testing was carried out twice, at a 15-day interval, for the presence of antibodies to MmmSC, brucellosis, bovine viral diarrhoea, bovine leukosis virus, bovine respiratory syncytial virus, parainfluenza type 3 virus and infectious rhinotracheitis virus. Only low antibody titres against parainfluenza type 3 virus were detected. Animals were also examined for the presence of endo- and ectoparasites, but no treatment was considered necessary.

On arrival at Mashare, all the animals were at first kept in the same paddock and fed with hay supplemented with lucerne. A common drinking trough was available. At the time of the experimentation nine cattle were moved to a separate paddock $1 \mathrm{~km}$ away and infected by intubation with $\mathrm{MmmSC}$. The remaining 20 animals were moved to the infected paddock 26 days later. Treatment of ten of them with CsA started on the day of exposure to infection.

All animals under experimentation were examined daily for respiratory distress and their rectal temperatures were taken at the same hour every morning. Only those exceeding $39.0^{\circ} \mathrm{C}$ were considered fe- 
brile. Bleeding was performed according to a predetermined schedule at daily and or weekly intervals. Necropsy and collection of tissues specimens were conducted at death or slaughter.

\section{Mycoplasma strain}

It is believed that passage of $M m m S C$ in culture media may modify some of its characteristics. It was therefore considered of importance to infect the experimental animals using a pleural serous exudate obtained during 2003, from a cow in the Caprivi region which had died during the course of a CBPP outbreak. The exudate stored at $-80^{\circ} \mathrm{C}$, was checked for purity by PCR according to Hotzel, Sachse \& Pfützner (1996). Absence of bacteriological contaminants was assessed using blood, mannitol, MacConkey and Sabouraud agar plates seeded with the exudate and incubated at $37^{\circ} \mathrm{C}$ for $96 \mathrm{~h}$. The mycoplasma strain was identified as $\mathrm{MmmSC}$ Caprivi 2003 Ex. Its infective titre was $10^{10}$ Colony Forming Units (CFU)/m $\ell$.

\section{Cattle infection by intubation}

The infection of the nine animals by intubation had the main purpose of simulating natural disease transmission to in-contact susceptible stock.

Intubation, monitored with the aid of a bronchoscope, was performed on the animal while standing and not sedated, by inserting a horse stomach tube into the trachea as far as the bifurcation of bronchi and keeping it in position until completion of the intervention.

Each animal was infected with $10 \mathrm{~m} \ell$ of the pleural fluid followed by $25 \mathrm{~m} \ell$ of Thiaucourt culture medium (1992) containing $2 \%$ agarose which had been broken up by gentle homogenization. Finally $40 \mathrm{~m} \ell$ of culture medium was used to flush down the suspension to the target site (Hübschle et al. 2003).

\section{Contact infection of naïve untreated cattle}

Ten naïve animals were exposed to infection by contact with the cattle which had been infected by intubation 26 days earlier. Cattle surviving to the disease were slaughtered on Day 84 post exposure (pe) when $40 \%$ of them had died.

\section{Contact infection of CsA-treated cattle}

The remaining ten animals were similarly exposed to infection by contact with the animals intubated 26 days earlier. CsA was administered daily, intramuscularly, at the dose of $4 \mathrm{mg} / \mathrm{kg}$ body mass from the day of exposure and for the entire observation period of 84 days when $40 \%$ of them had also died.

\section{Serological tests}

The modified Campbell \& Turner complement fixation (CF) test was performed according to OIE standards (OIE Manual of Diagnostic Tests and Vaccines for Terrestrial Animals 2004), on sera obtained from all the animals at weekly intervals and stored at $-20^{\circ} \mathrm{C}$. Complement fixing titres (CFT) are expressed as the reciprocal of serum dilution.

\section{IFN $\gamma$ test}

For the performance of the cell proliferation assay, a laboratory with all essential equipment was set up within the premises of the Ministry of Agriculture Mashare Field Station.

Blood samples were collected in lithium-heparin vacutainers (Terumo Ltd, Italy) on alternate days from five of the ten untreated cattle and five of the CsAtreated ones. The available facilities did not permit the handling, on a daily basis, of a larger number of samples.

\section{Lymphocyte collection}

Immediately after collection, blood samples were diluted 1:4 with a lysing buffer solution $\mathrm{pH}$ 7,2 (TRIS $0,017 \mathrm{M}$ and ammonium chloride $0,144 \mathrm{M}$ ) and centrifuged at $400 \mathrm{xg}$ for $10 \mathrm{~min}$ at $4{ }^{\circ} \mathrm{C}$.

Each resulting lymphocyte cell pellet was suspended and washed twice using RPMI-1640 Modified Medium (SIGMA, Missouri, USA). After the last centrifugation, the pellet was suspended in $5 \mathrm{~m} \ell$ of complete RPMI-1640 Modified Medium supplemented with $20 \%$ foetal bovine serum (EuroClone, UK) to which had been added $2 \mathrm{mM}$ of L-glutamine (L-Glutamine, HybriMax, SIGMA, Missouri, USA), amphotericin $(25 \mu \mathrm{g} / \mathrm{m} \ell)$ - penicillin (10 $000 \mathrm{UI} / \mathrm{m} \ell)$ - streptomycin (10 mg/m $\ell$ ) (APS, SIGMA) and gentamicin sulphate solution $(50 \mathrm{mg} / \mathrm{m} \ell)$ (SIGMA).

The lymphocytes were distributed into 96-wells microplates (Falcon, USA) at the rate of 300000 cells per well, incubated for $2 \mathrm{~h}$ at $37^{\circ} \mathrm{C}$ in $5 \% \mathrm{CO}_{2}$ and then stimulated with CBPP antigen.

\section{Antigen preparation}

One millilitre of MmmSC Caprivi 2003 Ex strain was cultured at $37^{\circ} \mathrm{C}$ for $48 \mathrm{~h}$ in $10 \mathrm{~m} \ell$ of Thiaucourt medium. Further amplification of the culture up to $2 \ell$, was carried out by successive passages of the 
culture in Thiaucourt medium using a 1:10 dilution factor. The $2 \ell$ culture was then centrifuged at 12500 $x g$ for 30 min at $4{ }^{\circ} \mathrm{C}$, the resultant pellet was resuspended in PBS and two further cycles of washing were carried out. After the last centrifugation the protein concentration of the pellet resuspended in PBS was assessed using the BCA-Assay kit (PIERCE, USA).

\section{Cell proliferation assay}

Using the Cell Proliferation ELISA, BrdU Kit, (Roche, Germany), the antigen concentration giving an optimal lymphocyte stimulation was found to be $2,5 \mu \mathrm{g} /$ $\mathrm{m} \ell$.

The samples under testing as well as negative and positive controls were distributed in duplicate in 96well microplates on which lymphocyte cells had previously been dispensed.

Concanavalin A (SIGMA, Missouri, USA) at the concentration of $10 \mu \mathrm{g} / \mathrm{m} \ell$, was used as positive control for antigen stimulation, whereas unstimulated lymphocytes were used for negative control. After $24 \mathrm{~h}$ incubation at $37^{\circ} \mathrm{C}$ in $5 \% \mathrm{CO}_{2}$ the supernatant was collected from each well and stored at $-20^{\circ} \mathrm{C}$ (Mosman 1983; Denizot \& Lang 1986).

\section{Quantification of IFN}

Quantification of IFN $\gamma$ was carried out on supernatant of the lymphocyte cultures stimulated with MmmSC using the Kit BioX Gamma Interferon ELISA (BioX Diagnostics, Belgium). A calibration curve was prepared using eight standards at a known concentration $(0.78,1.56,3.12,6.25,12.5,25,50$ and 100 arbitrary unit $/ \mathrm{m} \ell$ ). The samples under testing and the standards were dispensed in a volume of $100 \mu \ell$ per well on microplates activated with an anti-bovine IFN $\gamma$ antibody. After incubation at room temperature for $1 \mathrm{~h}$ and several rinsings, $100 \mu \ell$ per well of conjugated antibody were distributed into all wells.
After further incubation at room temperature for $1 \mathrm{~h}$ followed by a further rinsing, $100 \mu \ell$ of substrate were added to each well, the blocking solution was added 20 min later and the reading was done with a spectrophotometer at a wavelength of $450 \mathrm{~nm}$.

Samples were considered positive if IFN $\gamma$ release was above the cut off value. The average value expressed in arbitrary unit (AU) of the negative controls used in the quantification test plus 2 standard deviation was taken as the cut off value of the test (1.29 AU/m $\ell$ ).

\section{Bacteriological testing}

Tissue samples for bacteriological testing, from animals that had either died during the course of the experiment or been sacrificed at its termination were stored at $-80^{\circ} \mathrm{C}$ pending examination. The isolation and identification of the aetiological agent were carried out according to OIE standards (OIE Manual of Diagnostic Tests and Vaccines for Terrestrial Animals 2004). The tissue samples selected were: lung and retropharyngeal, mediastinal and peribronchial lymph nodes but only lung specimens were routinely tested and titrated to assess the presence, purity and concentration of MmmSC.

To asses tissue infectivity, $1 \mathrm{~g}$ of affected pulmonary tissue was macerated in presence of $10 \mathrm{~m} \ell$ of Thiaucourt medium, centrifuged at $400 \times \mathrm{g}$ for $15 \mathrm{~min}$, the supernatant collected and used to prepare serial dilutions from $10^{-1}$ to $10^{-10} ; 0.1 \mathrm{~m} \ell$ of each dilution was used to infect Petri dishes containing Thiaucourt medium. After incubation at $37^{\circ} \mathrm{C}$ for a week, the titre was expressed as $\mathrm{CFU} / \mathrm{g}$.

\section{Clinical examination}

A veterinary officer was permanently stationed at the site of the experiment. The clinical signs were recorded daily and their severity graded as a clinical index $(\mathrm{Cl})$ which varied from 1 to 4 (Table 1).

TABLE 1 Clinical index

\begin{tabular}{|c|l|}
\hline $\mathbf{1}$ & $\begin{array}{l}\text { Polypnoea, reinforced vesicular breathing with or without dry cough, mainly after exercise. Slow movements of nostrils. } \\
\text { Suspected pleural friction sounds on auscultation. }\end{array}$ \\
\hline $\mathbf{2}$ & $\begin{array}{l}\text { Laboured breathing with evident movements of nostrils. Rubbing, crackling or pleural friction sounds on auscultation. Dry } \\
\text { cough, mainly after exercise, mass loss. }\end{array}$ \\
\hline $\mathbf{3}$ & $\begin{array}{l}\text { Marked laboured breathing, movement intolerance, dry cough even at rest, loud crackling or pleural fluid sounds at thoracic } \\
\text { level examination, mass loss. }\end{array}$ \\
\hline $\mathbf{4}$ & Inappetence, respiratory distress, severe wheezing, ptyalism, moist cough, foul smelling breath. \\
\hline
\end{tabular}




\section{Necropsy}

The nature of lung lesions and the percentage of parenchyma involved in the pathological process were recorded on ad hoc forms. The lesions recorded in the lungs of affected animals were:

- Acute lesions-hepatization at different stages, thickening of interlobular septa, presence of serous pleural exudate in the thoracic cavity and of fibrinous pleuritis

- Subacute lesions-fibrinous adhesions between visceral and parietal pleura, necrotic areas in lung parenchyma

- Chronic lesions-encapsulated sequestra at different stages of organisation or liquefaction.

\section{RESULTS}

\section{Cattle infection by intubation}

Nine animals were infected. The results obtained are summarized in Table 2. No outward reaction was recorded following manipulation related to their intubation.

CF antibodies were first detected on Day 7 post-infection (pi) in two animals and by Day 13 in the remaining ones.

Between Days 9 and 18 pi, eight animals showed pyrexia lasting from 8 to 16 days. One animal (N.9) was not clinically reactive.

Respiratory distress was recorded between Days 8 and 36 pi. Signs of variable intensity were characterized by coughing, polypnoea, laboured and sometimes abdominal breathing, dilated nostrils, reduced appetite, and ptyalism. Bovine 3 died on Day 22 pi after showing signs of acute disease whereas Bovine 9 did not show any during the entire observation period.

At necropsy Bovine 3, which died on Day 22, showed the typical lesions of acute CBPP. On Day 73 pi all the eight surviving cattle were slaughtered. Encapsulated sequestra and pleural adherence were present in all of them, including Bovine 9. In all instances CBPP was confirmed by isolation of $\mathrm{MmmSC}$ from the affected pulmonary tissues. The results obtained are indicative that infection of the cattle had been successful.

\section{Contact infection of untreated cattle}

The results of the ten animals exposed to the cattle which had been infected by intubation 26 days earlier are summarized in Table 3.
A CF antibody response was detected between Days 14 and 42 post-exposure (pe) in nine of the animals. Bovine 17 was a late reactor, antibodies only being detected on Day 77 pe.

An increase in the rectal temperature was first recorded between Days 30 and 59 pe in seven of the ten cattle. Bovine 17 manifested a delayed reaction, a mild temperature rise being recorded from Day 75 onwards. In the remaining two (N.16 and N.18) no febrile reaction was detected during the 84 days of observation despite evidence of respiratory distress. Temperature reactions, when present, lasted between 7 and 13 days.

Respiratory distress of mild intensity corresponding to a severity of $\mathrm{Cl} 1$ was first observed on Day 20 and varied between $\mathrm{Cl} 2$ and 4 in the successive days.

The four animals, which died in the course of the experiment showed severe and extensive acute lesions. However, one sequestrum, having a diameter more than $250 \mathrm{~mm}$, was also present in Bovine 12. On Day 84 pe, the six surviving animals were slaughtered and in all of them sequestra with thick fibrous capsules, involving $30-40 \%$ of the affected lung, were present. In Bovine 17, acute lesions were also present. In all instances the diagnosis of CBPP was confirmed by isolation of $\mathrm{MmmSC}$ from affected pulmonary lesions, infective titres in lung specimens varied between $10^{5.0}$ and $10^{8.0} \mathrm{CFU} / \mathrm{g}$ of lung tissue.

\section{IFN $\gamma$ test}

Results are shown in Fig. 1. Release of IFN $\gamma$ showed great variability.

Of the six surviving animals, in which chronic lesions were observed, release of IFN $\gamma$ was recorded in three of them (N.17, 18 and 19) on three separate occasions, whereas in the remaining three (N.13, 15 and 16), this occurred on only one occasion.

In the four animals which died during the observation period showing acute lesions, IFN $\gamma$ release was recorded on one occasion only in two of the cattle (N.14 and 20).

The first release was recorded on Day 35 pe in all eight reactive animals.

\section{Contact infection of cattle treated with CsA}

Ten treated cattle were exposed to infection through contact with animals infected by intubation 26 days earlier. The results are summarized in Table 4. 
Responses of cattle to infection with Mycoplasma mycoides var. mycoides small colony

TABLE 2 Events following infection of cattle by intubation

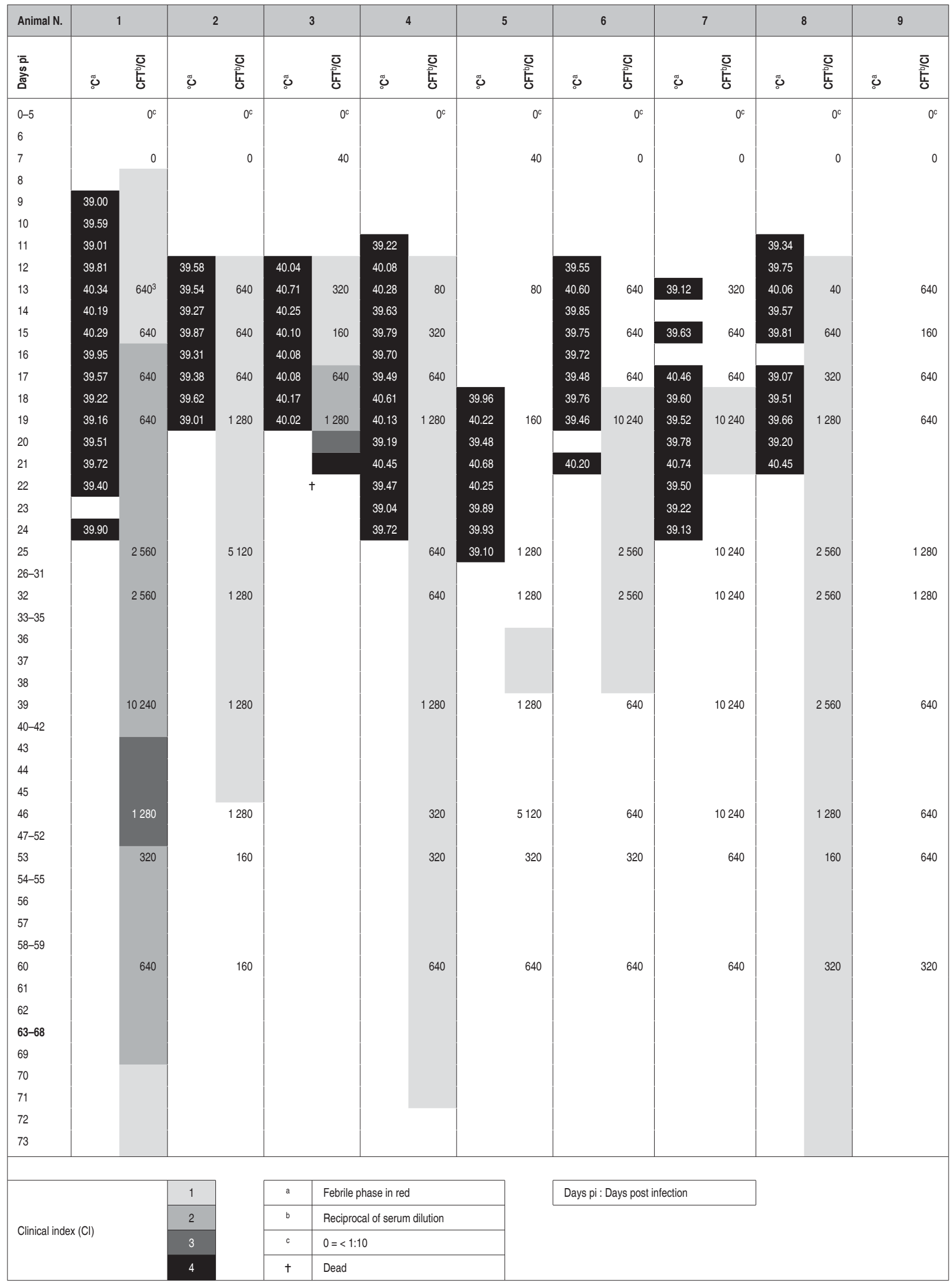


M. SCACCHIA et al.

TABLE 3 Events following contact infection of untreated cattle

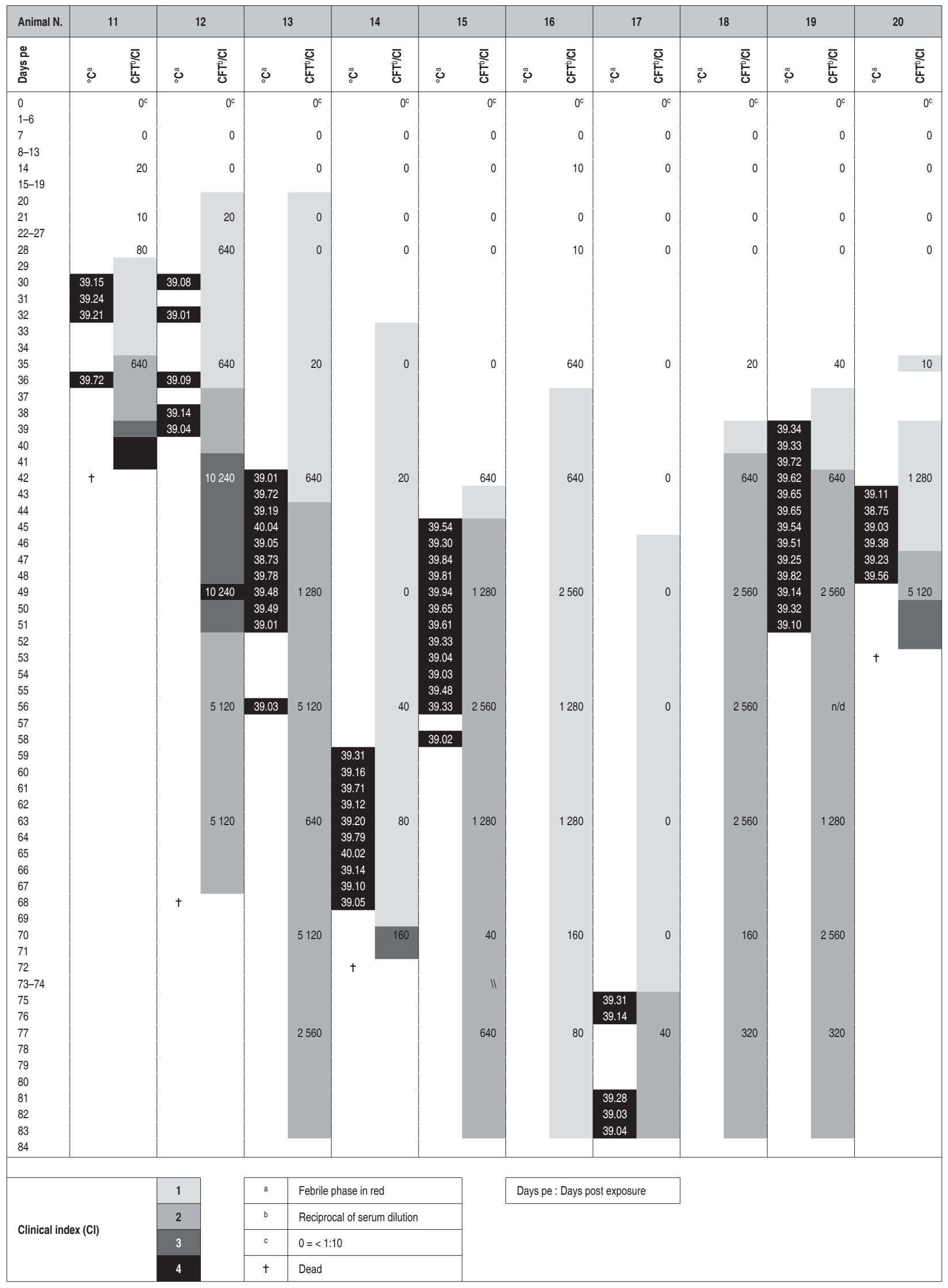



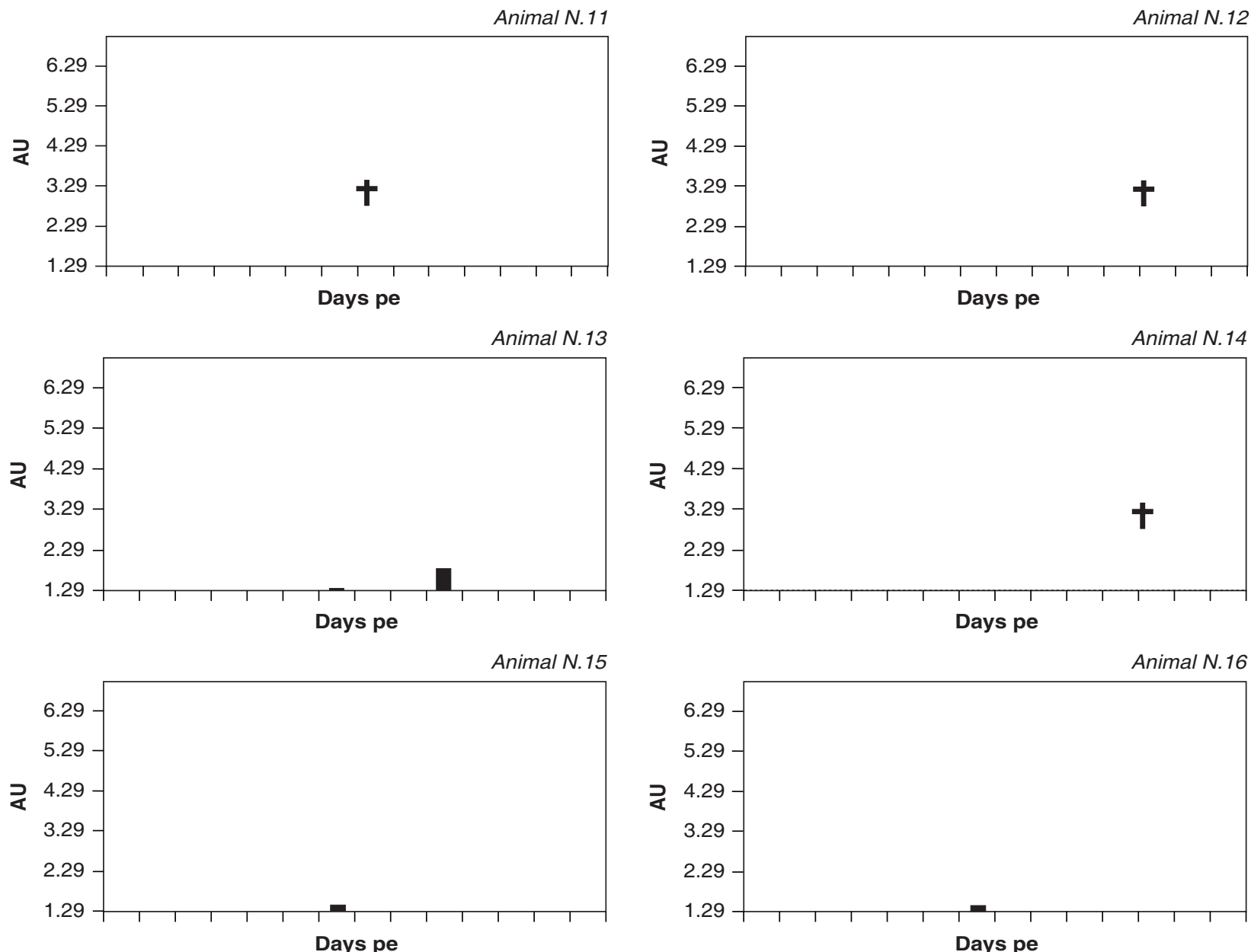

Animal N.17
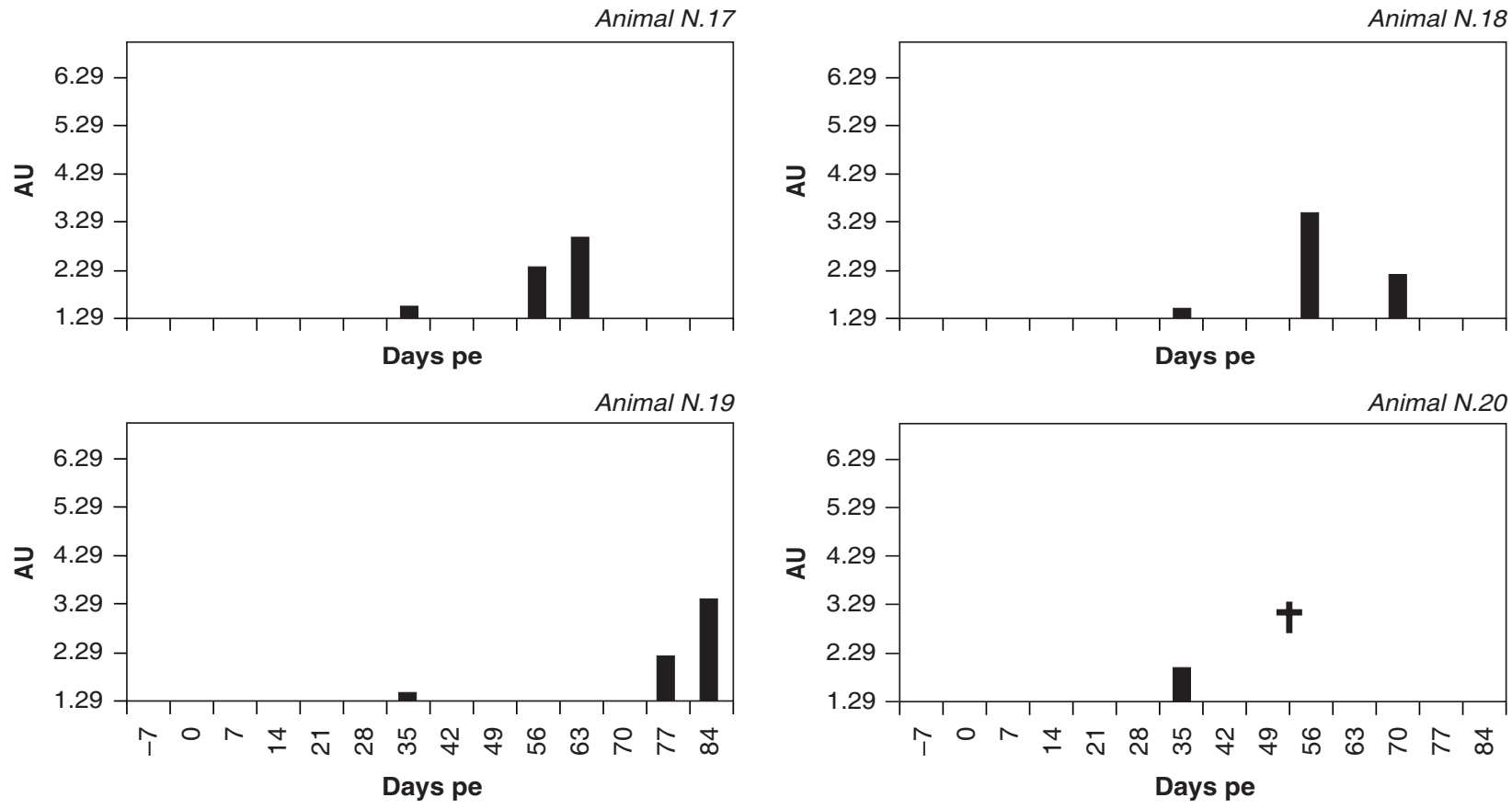

FIG. 1 IFN $\gamma$ release by lymphocytes stimulated with $\mathrm{Mmm} \mathrm{SC}$ in untreated cattle infected by contact. Lymphocytes isolated from blood were cultured with $\mathrm{Mmm} \mathrm{SC}$ and incubated for $24 \mathrm{~h}$. IFN $\gamma$ from supernatant was measured using the ELISA technique. † = Date of death; Days pe $=$ Days post exposure; $\mathrm{AU}=$ Arbitrary units 
M. SCACCHIA et al.

TABLE 4 Events following contact infection of cattle treated with CsA

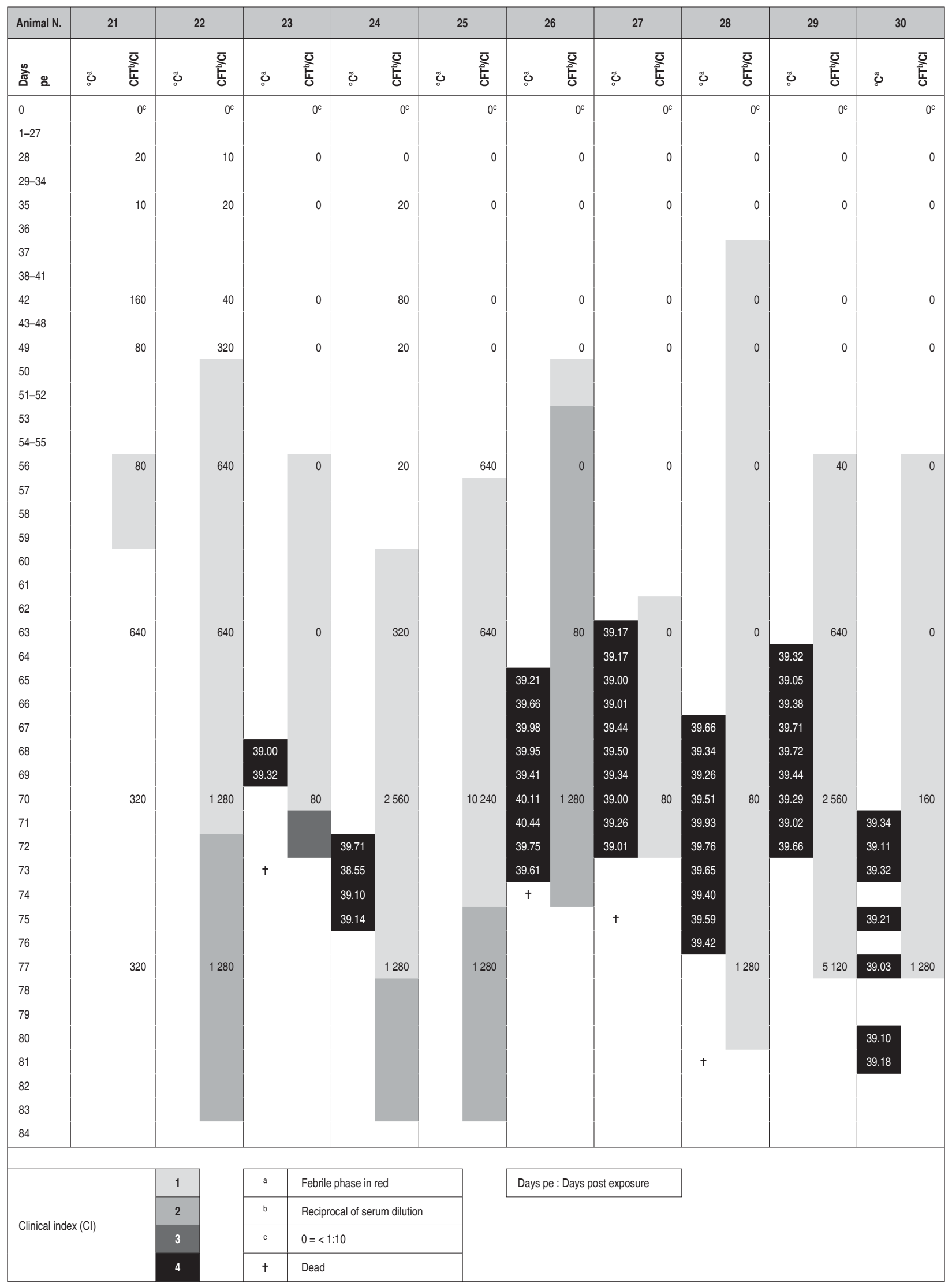



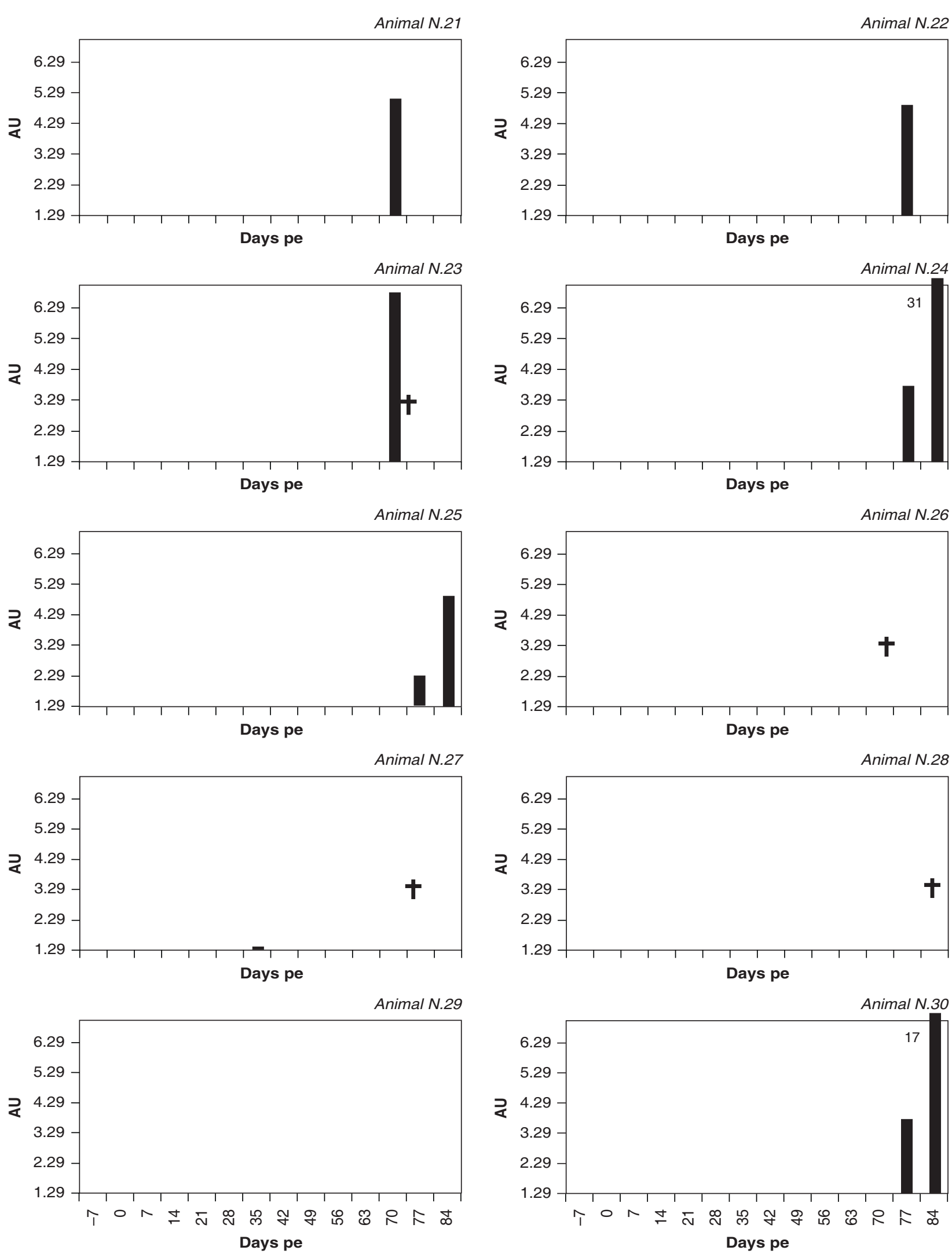

FIG. 2 IFN $\gamma$ release by lymphocytes stimulated with Mmm SC in cattle infected by contact and treated with CsA. Lymphocytes isolated from blood were cultured with Mmm SC and incubated for $24 \mathrm{~h}$. IFN $\gamma$ from supernatant was measured using the ELISA technique. + = Date of death; Days pe = Days post exposure; $\mathrm{AU}=$ Arbitrary units 
CF antibodies were first detected on Day 28 pe in Bovine 21 and 22 and Day 35 in Bovine 24. In the remaining seven cattle serological reactivity was first detected between Days 56 and 70 pe.

Temperature reactions were recorded between Days 63 and 72 pe in seven of the ten animals, three were not reactive over the observation period of 84 days. Pyrexia, when present, persisted for 2-11 days.

Respiratory distress of varying intensity corresponding to a severity of $\mathrm{Cl} 1$ and $\mathrm{Cl} 3$, was first observed between Day 37 and 60 pe. In three cattle (N.21, 22 and 25) this distress was observed in absence of a febrile reaction.

Three animals died in successive Days 73 (N.23), 74 (N.26), 75 (N.27) and one on Day 81 (N.28).

The animals which died during the observation period, showed typical acute lesions. All the slaughtered cattle had sequestra with thin and irregular capsule. Small areas with acute type lesions also being present in Bovines N.24 and 30.

Bacteriological tests of affected lung tissue confirmed the diagnosis of CBPP; infective titres varying between $10^{5.0}$ and $10^{8.0} \mathrm{CFU} / \mathrm{g}$ of tissue.

\section{IFN $\gamma$ test}

Results are shown in Fig. 2.

In the four animals which died during the observation period showing acute lung lesions, release of IFN $\gamma$ was recorded at a high level in Bovine 23 on Day 70, whereas in Bovine 27 it was just above the cut off value on Day 35 only. The remaining two (N.26 and 28) were not reactive. In the six cattle surviving throughout the observation period and in which predominantly chronic lesions were observed, release of IFN $\gamma$ was recorded at high level but it was delayed in onset to Days 70-77 when compared to that in the animals in the untreated group. Only Bovine 29 was not reactive.

\section{Statistical analysis of results}

The analysis of the parameters taken into consideration and summarized as the average of the results for each of the three groups of experimental cattle (Table 5), indicated that CsA-treated animals had, according to the Mann-Whitney bilateral test (Siegel \& Castellan, Jr 1988), a statistically significant delayed response $(P<0.01 ; Z=-3.042)$.

\section{DISCUSSION}

The dose of CsA used in the present experiment was lower than the doses given orally for monogastric animals as well as humans (Dean, Scott, Keogh, Roberts \& Tuch 2002). It was not increased any further in consideration of the field conditions in which the treated animals were kept, which may make them susceptible to complicating/subclinical pathologies. Due to the polygastric nature of the ruminant digestive system an oral application of the CsA was ruled out.

It must be noted that the MmmSC-infected pleural exudates, obtained from an affected cow during the course of a natural disease outbreak of CBPP in Namibia, was highly pathogenic and established an early infection and mortality to in-contact animals which enabled length of the observation period in the experiment to be limited to 84 days.

In the ten animals of the untreated group clinical signs were more severe than those observed in the ten animals of the CsA-treated group, both in those

TABLE 5 Summarized average of clinical, pathological and immunological parameters in the three group of animals

\begin{tabular}{|l|l|l|l|}
\hline Parameter & $\begin{array}{l}\text { Intubated } \\
\text { (days pi) }\end{array}$ & $\begin{array}{l}\text { Untreated } \\
\text { (days pe) }\end{array}$ & $\begin{array}{l}\text { CsA treated } \\
\text { (days pe) }\end{array}$ \\
\hline First day of antibody response & 7.0 & 14.0 & 28.0 \\
\hline Average time for sero-conversion & 11.6 & 34.8 & 54.6 \\
\hline First day of pyrexia & 9.0 & 30.0 & 63.0 \\
\hline Average time for temperature rise & 12.2 & 45.3 & 67.1 \\
\hline $\begin{array}{l}\text { Interval between infection/exposure and } \\
\text { death }\end{array}$ & 21.0 & 58.5 & 75.7 \\
\hline IFN $\gamma$, first release & Not done & 35.0 & $70.0-75.0$ \\
\hline
\end{tabular}

Days pi = Days post infection

Days pe $=$ Days post exposure 
surviving up to the time of slaughter as in those dying during the course of the experiment.

All the cattle dying during the course of the experiment showed, at necropsy, acute lesions whereas, in those slaughtered on Day 84 pe, the lesions were of a chronic nature with characteristic sequestra being present. However, in the exposed untreated cattle the capsule of the sequestra was well formed and thick, whereas in the CsA-treated ones it was irregular and thin. This is probably a further indication of a delaying effect of the drug.

From all the animals, irrespective of the type of pulmonary lesions observed, the MmmSC-infective titres detected in the affected tissues were comparable.

It can be noted that, in the two groups of animals that were infected by contact, the humoral immune response or respiratory distress, or both, preceded the temperature reaction.

Release of IFN $\gamma$ in the animals of the untreated group was detected in eight of the ten animals, release being first recorded on Day 35 pe. The levels and numbers of peaks of IFN $\gamma$ release however, varied. In the animals that died during the observation period cytokine release was either present or absent. In those cattle that manifested more than one IFN $\gamma$ peak, chronic lesions observed at necropsy were severe. From the results of the experiment, a correlation apparently exists between chronic lesions and IFN $\gamma$ release as has been reported by Dedieu et al. (2005). However, whether animals with extensive chronic lesions can be defined as recovering is matter for debate.

In the ten CsA-treated animals, release of IFN $\gamma$ was detected in seven, it being delayed to Days 70-77 pe with the exception of one animal which presented a single peak, just above the cut-off value, on Day 35. Levels of IFN $\gamma$ release were higher when compared with those recorded in the untreated group. Release was compatible with acute lesions as failure in detecting it was compatible with chronic changes.

It can be assumed that the delays in the cytokine release and its higher levels might be due to a saturation of immunophilins with a consequent sudden decrease of the immune-suppressing effect of CsA, hypothetically confirming the assumption upon which this experiment was based.

From the results reported, it is concluded that, under the conditions of the experiment, CsA had a statistically significant delaying effect on the clinical, hu- moral, pathological changes and cell-mediate response of cattle exposed to infection with MmmSC.

These results further support the hypothesis that an immunopathological process plays a role in the pathogenesis of CBPP.

\section{ACKNOWLEDGEMENTS}

The authors thank Mr C. Smit, Chief, Mashare Experimental Farm, Ministry of Agriculture, Water and Forestry, Kavango Region, Namibia, for providing the necessary facilities and unconditioned support and Ms Ischa Ulrich for her highly qualified technical assistance.

\section{REFERENCES}

ABUSUGRA, I., WOLF, G., BOLSKE, G., THIAUCOURT, F. \& MOREIN, B. 1997. ISCOM vaccine against contagious bovine pleuropneumonia (CBPP). Biochemical and immunological characterisation. Veterinary Immunology Immunopathology, 59:31-48.

ADEGBOYE, D.S. 1978. A review of mycoplasma induced immunosuppression. British Veterinary Journal, 134:556-560.

ANONYMOUS 1987. Annual Report of the Directorate of Veterinary Services, South West Africa/Namibia.

BALCER, V. \& DEDIEU, L. 2000. Cell mediated immunity induced in cattle by Mycoplasma mycoides subsp. mycoides: Comparison between infected and vaccinated animals, in Mycoplasma of ruminants: pathogenicity, diagnostics, epidemiology and molecular genetics (Cost 826), edited by D. Bergonnier, X. Berthelot \& J. Frey. Luxembourg: European Union, Agriculture and Biotechnology. EUR 19245, 4:97-100.

BAUMANN, G., ZENKE, G., WENGER, R., HIESTAND, P., QUESNIAUX, V., ANDERSEN, E. \& SCHREIER, M.H. 1992. Molecular mechanisms of immunosuppression. Journal Autoimmunity, 5, (Supplement A) :67-72.

BRANDAO, E. 1995. Isolation and identification of Mycoplasma mycoides subspecies mycoides SC strains in sheep and goats. Veterinary Record, 136:98-99.

DEAN, S.K., SCOTT, H., KEOGH, G.W., ROBERTS, S. \& TUCH, B.E. 2002. Effect of immunosuppressive doses of cyclosporine on pancreatic beta cell function in pigs. American Journal Veterinary Research, 63:1501-1506.

DEDIEU, L., BALCER-RODRIGUES, V., YAYA, A., HAMADOU, B., CISSE, O., DIALLO, M. \& NIANG, M. 2005. Gamma interferon producing CD4 T-cells correlate with resistance to $M y$ coplasma mycoides subsp. mycoides SC infection of cattle. Veterinary Immunology Immunopathology, 107:217-233.

DENIZOT, F. \& LANG, R. 1986. Rapid colorimetric assay for cell growth and survival. Modification to the tetrazolium dye procedure giving improved sensitivity and reliability. Journal Immunological Methods, 89:271-277.

GOURLAY, R.N. \& SAFRINE, M. 1966. Antigenic cross-reactions between the galactan from Mycoplasma mycoides and polysaccharides from other sources. Journal of Comparative Pathology, 76:417-425.

HOTZEL, H., SACHSE, K. \& PFÜTZNER, H. 1996. A PCR scheme for differentiation of organisms belonging to the Mycoplasma mycoides cluster. Veterinary Microbiology, 49:31-43. 
HOWARD, C.J. \& TAYLOR, G. 1985. Humoral and cell mediated immunity, in The mycoplasmas, edited by S. Razin \& M.F. Barile. Orlando, Florida: Academic Press.

HÜBSCHLE, O., LELLI, R., FREY, J. \& NICHOLAS, R.A.J. 2002. Contagious bovine pleuropneumonia and vaccine strain T1/44. Veterinary Record, 150:615.

HÜBSCHLE, O.J.B., TJIPURA-ZAIRE, G., ABUSUGRA, I., FRANCESCA, G., METTLER, F., PINI, A. \& MOREIN, B. 2003. Experimental field trial with an immunostimulating complex (ISCOM) vaccine against contagious bovine pleuropneumonia. Journal Veterinary Medicine, 50:298-303.

MOSMANN, T. 1983. Rapid colorimetric assay for cellular growth and survival: application to proliferation and cytotoxicity assay. Journal of Immunological Methods, 65:55-63.

NICHOLAS, R.A.J., TIJPURA-ZAIRE, G., MBULU, R.S., SCACCHIA, M., METTLER, F. \& FREY, J. 2004. An inactivated whole cell vaccine and $L p p Q$ subunit vaccine appear to exacerbate the effect of CBPP in cattle. Report of the 3rd meeting of the FAO/OIE/AU-IBAR/IAEA Consultative Group on Contagious Bovine Pleuropneumonia. Theme: Towards Sustainable CBPP Control Programme for Africa, 12-14 November 2003. Rome, Italy: FAO.

OIE 2004. Manual of Diagnostic Tests and Vaccines for Terrestrial Animals, $4^{\text {th }}$ ed.

http://www.oie.int/eng/normes/mmanual/A_00029.htm

PROVOST, A., PERREAU, P., BREARD, A., LEGOFF, C., MARTEL, J.L. \& COTTEW, G.S. 1987. Contagious bovine pleuropneumonia. Revue Scientific et Technique, Office International Epizooties, 6:625-679.
ROBERTS, D.H. \& WINDSOR, R. 1974. Attempts to differentiate Mycoplasma mycoides var. mycoides immune cattle from susceptible cattle. Research in Veterinary Science, 17:403-405.

SANTINI, F.G., VISAGGIO, M., FARINELLI, G., DI FRANCESCO, G., GUARDUCCI, M., D'ANGELO, A.R., SCACCHIA, M. \& DI GIANNATALE, E. 1992. Pulmonary sequestrum from Mycoplasma mycoides var. mycoides SC in domestic buffalo; isolation anatomo-histopathology and immuno-histochemistry. Veterinaria Italiana, 4:4-10.

SIEGEL, S. \& CASTELLAN, JR, N.J. 1988. Nonparametric statistics for behavioural science, $2^{\text {nd }}$ ed. New York, USA: McGrawHill.

SRIVASTAVA, N.C., THIAUCOURT, F., SINGH, V.P., SUNDER, J. \& SINGH, V.P. 2000. Isolation of Mycoplasma mycoides small colony from contagious caprine pleuropneumonia in India. Veterinary Record, 147:520-521.

THIAUCOURT, F., GUERIN, C., MADY, V. \& LEFEVRE, P.C. 1992. Diagnostic de la pleuropneumonie contagieuse caprine: améliorations récentes. Revue Scientific et Technique, Office International Epizooties, 11:859-65.

THIAUCOURT, F., YAYA, A., WESONGA, H., HÜBSCHLE, O. J.B., TUALASNE, J.J. \& PROVOST, A. 2000. Contagious bovine pleuropneumonia, a reassessment of the efficacy of vaccines in Africa. Annals of the New York Academy of Science, 916:71-80.

TULASNE, J.J., LITAMOI, J.K., MOREIN, B., DEDIEU, L., PALYA, V.J., YAMI, M., ABUSUGRA, I., SYLLA, D. \& BENSAÏD, A. 1996. Contagious bovine pleuropneumonia vaccines: the current situation and the needs for improvement. Revue Scientific et Technique, Office International Epizooties, 15: 1373-1396. 